Perkembangan Fatayat Nu Kabupaten Subang Dalam Bidang Kaderisasi Periode 2015-2020 | Wiwit Nurhayati Hidayat, Amung Ahmad Syahir, Dina Maliana

\title{
Perkembangan Fatayat Nu Kabupaten Subang Dalam Bidang Kaderisasi Periode 2015-2020
}

\author{
Wiwit Nurhayati Hidayat, Amung Ahmad Syahir, Dina Maliana \\ Fakultas Adab dan Humaniora \\ Universitas Islam Negeri Sunan Gunung Djati Bandung \\ Email : wiwitnuhayati212@gmail.com
}

\begin{abstract}
Fatayat NU is one of the Nahdlatul Ulama autonomous bodies. As we know, Nahdlatul Ulama is the largest sosial and religious social organization in Indonesia. Like its parent, Nahdlatul Ulama, now Fatayat NU has branches that are spread in almost every city in Indonesia, one of which is in Subang Regency. This study aims to determine how the history of Fatayat NU and the develompent of Fatayat NU Subang Regency, especially in the field of regeneratios for the 2015-2020 period. The method used this study is a qualitative method, namely by collecting data through literature, documentation and interview. The data analysis technique is done by the heuristic, criticism, interpretation and historiography methods. The results of the period 2015-2020 Fatayat NU Subang Regency succeeded inaugurating as many as 30 PACs throughout Subang Regency in 2019. Where as previously only 10 PACs were successfully appointed as cadres Fatayat NU Subang Regency.
\end{abstract}

Keywords: Fatayat NU, Regeneration 


\section{Pendahuluan}

Di Indonesia terdapat organisasi sosial kemasyarakatan dan keagamaan (ormas), salah satu ormas terbesar yang ada di Indonesia adalah Nahdlatul Ulama (NU). NU adalah gerakan dari ulma-ulama Islam di Indonesia yang dipelopori oleh K. H Wahid Hasyim Asy’ari dari Jombang, Jawa Timur. Sekalipun $\mathrm{Nu}$ mempertahankan "ortodoksi-ortodoksi" abad pertengahan, namun dalam konteks membangkitkan semangat umat Islam, gerakan ini berhasil. Melalui lembaga-lembaga pendidikan pondok pesantren, NU berhasil menanamkan semangat dan watak antikolonialisme. Dengan berpegang teguh pada ajaran Islam dan memelihara semangat ahlus sunnah wal jamaah, NU berhasil menggalang persatuan dan kesatuan umat Islam Indonesia. ${ }^{1}$

Konteks dalam pendirian NU ini ada dua, yaitu untuk tujuan kemerdekaan dan untuk memagari Islam Ahlu Sunnah Waljamaah dan menjaga keagamaan dari serangan Wahabi di Indonesia. Setelah NU lahir, NU memperluas cakupannya hingga beberapa kota untuk mendirikan cabang-cabang yang telah menyetujui untuk mendirikan himpunannya di daerah itu, sampai dapat membentuk kring di cabang Gresik, Sidoarjo dan Surabaya, yang dulu pada tahun tersebut disebut kring (cabang NU tingkat desa/kelurahan). ${ }^{2}$

Seiring berjalannya waktu Nahdlatul Ulama (NU) semakin banyak anggotanya, ini tersebar di cabang-cabang NU hampir setiap daerah di seluruh Indonesia. Struktur organisasi NU ini mulai dari Pengurus Besar yakni tingkat Pusat, pengurus wilayah yakni pada tingkat Provinsi, pengurus cabang di tingkat Kabupaten atau Kota dan cabang Istimewa (Luar Negeri), pengurus majelis wakil cabang di tingkat Kecamatan dan pengurus ranting yakni tingkat desa atau kelurahan. ${ }^{3}$

Di dalam Nahdlatul Ulama terdapat Badan Otonom. Badan Otonom ini berfungsi melaksanakan kebijakan Nahdlatul Ulama yang berkaitan dengan kelompok masyarakat tertentu dan beranggotakan perorangan. Badan Otonom dikelompokkan dalam beberapa kategori ada yang berbasis usia dan kelompok masyarakat tertentu, dan Badan Otonom berbasis profesi dan

\footnotetext{
${ }^{1}$ H. Alamsjah Ratu Perwiranegara, Islam Dan Pembangunan Politik Di Indonesia (Jakarta: CV Haji Masagung, 1987), 186-87.

${ }^{2}$ Al Miskiyah, Sejarah Serdirinya Nahdlatul Ulama Cabang Surabaya (Surabaya:

Universitas Islam Negeri Sunan Ampel, 2017), 17.

${ }^{3}$ Nu.or.id, "Struktur Organisasi," n.d.
} 
kekhususan lainnya. Salah satu badan otonom dibawah naungan Nahdlatul Ulama yaitu Fatayat NU. ${ }^{4}$

Fatayat Nahdatul Ulama adalah sebuah organisasi pemudi (perempuan muda) Islam yang merupakan salah satu badan otonom di lingkungan Nahdatul Ulama. Fatayat NU ini lahir untuk merespons berbagai persoalan yang dihadapi perempuan dan kebutuhan untuk mengembangkan potensi dan sumber daya perempuan. Di sinilah, Fatayat NU memiliki dua dimensi secara bersamaan, yaitu sebagai instrumen kaderisasi NU di satu sisi dan sebagai organ gerakan perempuan di sisi yang lain, tentu dua dimensi ini tidak dapat dipisahkan satu sama lain. ${ }^{5}$

Seperti induknya yakni Nahdlatul Ulama, kini Fatayat NU memiliki cabang yang tersebar hampir di setiap kota yang ada di Indonesia, salah satunya yaitu cabang Subang. Berdirinya Fatayat $\mathrm{Nu}$ Kabupaten Subang memiliki sejarah yang cukup panjang. Lahirnya Fatayat NU Kabupaten Subang ini sekitar tahun 1985 yang diketuai oleh ibu Umi Kulsum. Pada awal berdirinya Fatayat NU Kabupaten Subang bisa dikatakan sangat memprihatinkan, karena tanpa adanya bimbingan dan arahan dari siapapun. Walaupun tanpan bimbingan dan arahan, Fatayat NU Kabupaten Subang mampu berjalan sampai saaat ini.

\section{Metode}

Dalam melakukan penelitian, penulis menggunakan metode penelitian sejarah. Jika diuraikan maka, metode sejarah terdiri dari empat tahap yaitu, heuristik, kritik, interpretasi, dan historiografi. Berikut adalah penjelasan dari tahapan-tahapan tersebut.

\section{a. Heuristik}

Tahapan pertama yang penulis lakukan dalam penelitian adalah heuristik, yakni mencari sumber yang berkaitan dengan judul penelitian. Sebab tanpa sumber, penelitian ini tidak akan menjadi karya sejarah. Oleh karena itu, pada tahap ini yang dilakukan adalah mencari dan mengumpulkan sumber yang berkaitan dengan judul penelitian. Hasil dari uraian diatas mengenai heuristik, penulis menemukan berbagai sumber, baik sumber

\footnotetext{
${ }^{4}$ Nu.or.id, "No Title," 16 Januari, 2020.

${ }^{5}$ Anggia Ermarini dkk, Hasil Kongres Xv Fatayat Nahdlatul Ulama (Jakarta: Pimpinan Pusat Fatayat Nahdlatul Ulama, n.d.), 5.
} 
primer maupun sumber sekunder yang dapat dijadikan rujukan dalam proses penyusunan penelitian ini adalah sebagai berikut:

Sumber berupa tulisan.

1. Surat Keputusan Susunan Pengurus Pimpinan Cabang Fatayat NU Kabupaten Subang Masa Khidmat 2015-2020. Ini didapatkan dari pihak Fatayat NU Kabupaten Subang

2. Hasil Kongres XV Fatayat Nahdlatul Ulama 2015-2020. Ini merupakan buku panduan Fatayat NU periode 2015-2020.

3. Buku yang diterbitkan Pucuk Pimpinan Fatayat Nahdlatul Ulama, Sejarah Fatayat NU (Jakarta: PP Fatayat NU, 1984)

\section{b. Kritik}

Pada tahap kedua yakni kritik. Tahapan kritik dibagi menjadi dua yaitu kritik ekstern dan kritik intern. Dalam tahap kritik ekstren ini maksudnya terdapat pada otentitas sumber yang kita dapat, yakni sumbernya layak atau tidak, sumbernya asli atau palsu dan apakah sumbernya utuh atau tidak. Dalam tahap kritik intern yakni mengkritik dari isi sumber yang didapatkan dan juga penilaian terhadap isi sumber.

Setelah melakukan kritik ekstern dan kritik intern terhadap sumber yang terkumpul mengenai pembahasan perkembangan Fatayat NU Kabupaten Subang dalam bidang kaderisasi periode 2015-2020 , maka sumber tersebut dikelompokan menjadi sumber primer dan sumber sekunder.

Sumber Primer

1. Surat Keputusan Susunan Pengurus Pimpinan Cabang Fatayat NU Kabupaten Subang Masa Khidmat 2015-2020. Ini dijadikan sumber primer oleh penulis karena ini merupakan bukti Kepengurusan Fatayat NU Kabupaten Subang periode 2015-2020.

2. Hasil Kongres XV Fatayat Nahdlatul Ulama 2015-2020. Buku ini merupakan buku panduan Fatayat NU untuk periode 2015-2020.menjadi rujukan penulis karena didalamnya terdapat AD/ART dan juga sejarah Fatayat NU.

Sumber sekunder

3. Buku yang diterbitkan Pucuk Pimpinan Fatayat Nahdlatul Ulama, Sejarah Fatayat NU (Jakarta: PP Fatayat NU, 1984). Buku ini penulis kategorikan sebagai sumber sekunder.

\section{c. Interpretasi}


Tahap selanjutnya yakni interpretasi. Interpretasi atau penafsiran sering disebut sebagai bidang subjektivitas. Benar, karena tanpa penafsiran sejarawan, data tidak bisa dipercaya. Sejarawan yang jujur, akan mencantumkan data dan keterangan dari mana data itu diperoleh. Orang lain dapat melihat kembali dan menafsirkan ulang. ${ }^{6}$

Penelitian ini akan mengkaji mengenai Perkembangan Fatayat NU Kabupaten Subang dalam bidang kaderisasi periode 2015-2020. Oleh karenanya, untuk memudahkan kajian ini diperlukan teori. Adapun dalam penulisan yang digunakan ialah teori pengembangan organisasi. Pengembangan organisasi menurut Indra Wijaya merupakan cara pendekatan terhadap perubahan yang berjangka panjang dan lebih luas ruang lingkupnya dengan tujuan untuk menggerakan seluruh organisasi ke arah tingkat fungsional yang lebih tinggi. ${ }^{7}$

\section{d. Historiografi}

Tahap ini merupakan tahap terakhir dari metode penelitian. Historiografi yakni penulisan sejarah. Bentuk dari cerita sejarah ini akan ditulis secara kronologis dengan topik yang jelas terkait dengan pembahasan penulisan tentang perkembangan Fatayat NU Kabupaten Subang dalam bidang kaderisasi periode 2015-2020, dengan demikian akan mempermudah pembaca. Maka penulis menuliskannya menjadi sebuah sejarah kisah secara sistematika dan selaras.

\section{Hasil dan Pembahasan}

\section{A. Sejarah Fatayat NU}

\section{Lahirnya Fatayat NU}

Fatayat NU Didirikan di Surabaya 24 April 1950 M, bertepatan dengan 7 Rajab $1317 \mathrm{H}$. Organisasi yang menghimpun pemudi NU ini memiliki andil besar dalam mempertajam dan memberdayakan kaum perempuan NU. ${ }^{8}$ Dasar perjuangan Fatayat Nahdlatul Ulama ini berpedoman kepada Al-Qur'an yakni surat Al-Imron ayat 104 yang berbunyi: "Dan hendaklah ada diantara kamu segolongan umat yang mengajak kepada

\footnotetext{
${ }^{6}$ Kuntowijoyo, Pengantar Ilmu Sejarah (Yogyakarta: PT Bentang Pustaka, 1995), 101-2.

${ }^{7}$ Zulfiana Rahmawati dkk, Pengembangan Organisasi (Malang: Universitas Brawijaya, 2012), 4.

${ }^{8}$ Nur Khlaik Ridwan, Ensiklopedia Khittah Nahdlatu Ulama Jilid I (Jogjakarta: Ar-Ruzz Media, 2017), 195.
} 
kebaikan dan menyerukan kepada yang ma'ruf dan mencegah dari yang mungkar; merekalah orang-orang yang beruntung". (Q.S 3:104). ${ }^{9}$

Fatayat NU berorientasi pada sosial penghapusan segala bentuk kekerasan, ketidakadilan dan kemiskinan dalam masyarakat dengan mengembangkan wacana kehidupan sosial yang konstruktif, demokratis dan berkeadilan gender (sosial). ${ }^{10}$ Membicarakan Fatayat pada awal rintisanya tidak akan mudah melepaskan diri dari tiga orang yang begitu gigih memperjuangkan keberadaan Fatayat. Tiga orang ini sering disebut dengan julukan "Tiga Serangkai" mereka adalah Murtosiyah dari Surabaya, Chuzaimah Mansur dari Gresik dam Aminah Mansur dari Sidoarjo. ${ }^{11}$

Keinginan mendirikan Fatayat NU berawal dari tiga serangkai ini akan perjuangan kaum perempuan terutama dalam NU sendiri. Mereka melihat bahwa pemuda-pemuda NU telah mendapatkan wadah mereka dengan didirikannya Gerakan Pemuda Anshar, dan para wanita NU yang usia mereka lebih dewasa juga telah mendapatakan wadah mereka dengan adanya Muslimat NU. Tiga Serangkai ini merasa bahwa pemudi-pemudi NU yang usianya relative masih muda, ingin mempunyai wadah sendiri yang dapat mereka kendarai sesuai dengan watak dan kehendak mereka dalam merangkai dan melaksanakan programnya. ${ }^{12}$

Banyaknya dukungan dari para sesepuh di NU-lah yang membuat para pemudi NU ini membulatkan tekadnya untuk membentuk organisasi sendiri. Tujuan mereka dalam membangun Fatayat ini, yakni mereka ingin memperbaiki pendidikan perempuan muda dikalangan bawah yang berkultur santri. Prioritas utama dalam programnya ini Fatayat ingin memberantas buta huruf pada kalangan perempuan, ini karena kebanyakan dari mereka masih banyak yang tidak bisa membaca. Mereka memberdayakan perempuan dengan mengadakan kursus-kursus, seperti kursus menjahit, menyulam, memasak dan lain-lain. ${ }^{13}$

\footnotetext{
${ }^{9}$ Pucuk Pimpinan Fatayat Nahdlatul Ulama, , Profil Fatayat Nahdlatul Ulama (Jakarta: PP Fatayat NU, n.d.), 2.

${ }^{10}$ Gita Anggraini, "Peta Gerakan Perempuan Islam Pasca Orde Baru (Book Review),” 2020, 3, academia.edu.

${ }^{11}$ Pucuk Pimpinan Fatayat Nahdlatul Ulama, , Profil Fatayat Nahdlatul Ulama, 50.

${ }^{12}$ Intan Gustina Sari, Peran Kepemimpinan Fatayat Nahdlatul Ulama (NU) Dalam Mensosialisasikan Kesetaraan Gender (Jakarta: Universitas Islam Negeri Syarif Hidayatullah, 2011), 45.

${ }^{13}$ Anggia Ermarini dkk, Hasil Kongres Xv Fatayat Nahdlatul Ulama, 86.
} 
Banyaknya dukungan dari para pendahulunya bukan berarti tidak ada yang menentang berdirinya Fatayat. Salah satu pertentangan ini datang dari Kiai Bisri Samsuri. Dimana menurut Kiai Bisri lebih baik tidak mendirikan organisasi perempuan lagi, karena NU sudah mempunyai Muslimat NU. Akan tetapi, Fatayat sangat gigih menginginkan organisasi sendiri. Keinginan ini sangat didukung oleh K. H. Mohammad Dahlan. Dukungan Kiai Dahlan ini sangat berarti bagi "Tiga Serangkai" yang pada waktu itu yang memperjuangkan berdirinya Fatayat. Saat itu, Kiai Dahlan meminta izin kepada Kian Hasyim dan Kiai Wahab. Beliau menjelaskan bahwa keinginan "Tiga Serangkai" merupakan niat yang baik. Fatayat yang menginginkan organisasi sendiri, yakin bahwa mereka mampu terlibat langsung dalam menangani permasalahan baik pendidikan maupun politik. Hal ini menunjukkan adanya kemajuan berpikir perempuan. Kiai Hasyim dan Kiai Wahab pun menyetujui dibentuknya Fatayat dengan catatan bahwa disetiap kepengurusan Fatayat terdapat perwakilan dari NU dan Muslimat setempat. ${ }^{14}$

Orang yang paling berjasa atas berdirinya Fatayat yakni K. H. Mohammad Dahlan, bahkan yang memberi nama perkumpulan pemudi NU dengan "Fatayat" juga Kyai Dahlan. Pengesahan itu tak lepas dengan jasa K.H Mohammad Dahlan yang berjerih payah mengundang tiga serangkai ini dalam suatu rapat PBNU. Saat bersejarah yang tercatat pada bulan Februari 1950 yang bertepatan denagn 26 Rabiutsani 1369 H, melalui surat No. 574/U mengesahkan dibentuknya serta ditunjuknya Dewan Pimpinan Fatayat NU yang masih bersifat sementara menjelang Muktamar NU ke 18 di Jakarta (1950). Tiga Serangkai itu ditunjuk sebagai pejabat Dewan Pimpinan itu dibantu oleh Nihayah Bakri, Asnawiyah, Solichah Lukman dan Fatimah Husaini. ${ }^{15}$

Perjuangan tak hanya sampai disini, Dewan Pimpinan itu masih berupaya keras untuk mencapai ppengesahan pada Muktamar NU ke 18 dan 19 April 1951 di Jakarta. Akhirnya, Fatayat mendapat pengesahan dari Muktamar. Kemudian dalam sidang khusus Fatayat, istilah Dewan Fatayat diubah menjadi Pucuk Pimpinan. Dan setelah melalui proses demokrasi yang panjang, Nihayah Bakri terpilih sebagai Ketua Puncuk Pimpinan Fatayat NU

\footnotetext{
${ }^{14}$ Nailin Naziyah, "Fatayat NU Dalam Aspek Kemasyarakatan Di Surabaya Tahun 19591967," Jurnal Universitas Aielangga, 2015, 5-6.

${ }^{15}$ Pucuk Pimpinan Fatayat Nahdlatul Ulama, , Profil Fatayat Nahdlatul Ulama, 53.
} 
pertama. Tentu saja tidak melupakan jasa Tiga Serangkai. Tiga Serangkai masih menempati posisi yang penting juga dan susunan Pucuk Pimpinan yang baru itu. ${ }^{16}$

\section{Awal Mula Berdirinya Fatayat NU Kabupaten Subang}

Fatayat NU Kabupaten Subang berdiri pada tahun 1985 yang pada waktu itu diketuai oleh Ibu Umi Kulsum atas perintah Ketua PCNU Subang kala itu yaitu Kyai Bustomi. Awal berdirinya Fatayat Nu di Subang ini bisa dikatakan sangatlah menyedihkan, ini dikarenakan tidak adanya adanya bimbingan dan arahan dari siapapun. Bisa dikatakan bahwa Fatayat NU di Subang ini berdiri sendiri. Beruntungnya sang ketua Ibu Umi Kulsum mempunyai pengalaman dalam berorganisasi, sehingga dalam memimpin Fatayat NU beliau sangat bertanggung jawab. Ibu Umi Kulsum tidak sendiri pada awal pendirian Fatayat ini, beliau ditemani oleh rekannya yaitu Ibu Umamah sebagai sekretaris. ${ }^{17}$

Pada tahun 1985, diadakan Konferensi Wilayah di Provinsi Jawa Barat yang diselenggarakan di Hotel Harapan Bandung, dalam acara Bina Balita yang diselenggarakan oleh Unicef yang bekerjasama dengan Nahdlatul Ulama. Pada waktu itu Fatayat NU dibeberapa daerah diundang untuk menghadiri acara konferensi tersebut termasuk Subang. Karena pada waktu itu Fatayat NU Subang belum ada, maka Ketua NU pada waktu itu yakni Kyai Bustomi memilih langsung Ibu Umi Kulsum sebagai ketua Fatayat NU, yang pada waktu itu Ibu Umi Kulsum menjabat sebagai Ketua Ikatan Santri Putri Kabupaten Subang (ISPUKAS). Dirasa Ibu Umi Kulsum ini bisa menjadi pemimpin sebuah organisasi karena pengalamannya, maka dari itu Kyai Bustomi memilihnya dan menjadikannya sebagai ketua Fatayat NU Subang. ${ }^{18}$

Setelah ditunjuknya Ibu Umi Kulsum sebagai ketua Fatayat NU, beliau pun pergi ke acara Konferensi Wilayah tersebut sebagai perwakilan Fatayat Nu Subang ditemani oleh Ibu Umamah, sekretarisnya. Selama mengikuti Konferensi Wilayah di Bandung, mereka berdua tidak ditemani ataupun dibimbing oleh siapapun entah itu Muslimat sebagai pendahulunya ataupun dari pengurus NU nya sendiri, mereka benar-benar mandiri, tidak

\footnotetext{
${ }^{16}$ Pucuk Pimpinan Fatayat Nahdlatul Ulama, 53-54.

${ }^{17}$ Ummi Kulsum, "Fatayat Nu - Ketua Fatayat NU Kabupaten Subang Periode Awal" (Subang, n.d.).

${ }^{18}$ Kulsum.
} 
seperti perwakilan Fatayat NU cabang lainnya yang ditemani dan dibimbing oleh para seniornya. ${ }^{19}$

Setelah pulang dari Konferensi Wilayah itu, mereka langsung ditugaskan untuk mensosialisasikan kegiatan Bina Balita ke setiap majelis ta'lim sekaligus mengajak para perempuan muda untuk ikut dalam Fatayat NU. Total ada 5 Kecamatan yang pada waktu itu mereka sosialisasikan untuk kegiatan tersebut, yaitu Kecamatan Pamanukan, Pusaka Negara, Pusaka Jaya, Binong dan Sukasari. Selain itu, dilakukan juga kegiatan dakwah dalam bentuk pengajian-pengajian ke setiap majlis ta' lim. ${ }^{20}$

Awal pendirian Fatayat pun diisi dengan kegiatan-kegiatan pengajian. Adapun bentuk pengajiannya yaitu Jam'iyahan, diba'iyahan, membaca syai'ir-sya'ir tentang kelahiran Nabi Muhammad SAW. Selain itu juga Fatayat NU fokus mengajak perempuan-perempuan muda untuk ikut serta, walaupun masih banyak perempuan muda yang susah untuk diajak. Kegiatan lain yang dilakukan Fatayat juga yakni menggelar PHBI (Perayaan Hari Besar Islam) seperti Isra' Mi'raj, Kelahiran Nabi Muhamamd SAW, Rajaban dan lain-lain.

\section{B. Profil Fatayat NU Kabupaten Subang \\ 1. Visi \& Misi Fatayat NU Subang}

Adapun Visi \& Misi Fatayat NU Subang ini untuk mencapai tujuannya, yakni:

\section{Visi}

Terbentuknya perempuan Muda NU yang bertakwa kepada Allah SWT, Berakhlakul karimah, beramal sholeh, cakap, bertanggung jawab, berguna bagi agama, nusa, bangsa dan negara.

\section{Misi}

Mewujudkan perempuan berkarakter, bermartabat mempunyai rasa kesetiaan terhadap azas, aqidah, menegakkan syariat Islam menurut faham ahlussunah waljama'ah, serta membela NKRI. ${ }^{21}$

\section{Maksud dan Tujuan Fatayat NU}

1. Terbentuknya pemudi atau wanita muda Islam yang bertaqwa kepada Allah SWT, berakhlakul karimah, bermoral, cakap bertanggung jawab, berguna bagi agama, nusa dan bangsa.

\footnotetext{
${ }^{19}$ Kulsum.

${ }^{20}$ Kulsum.

${ }^{21}$ Hj Unengsih, "Ketua Fatayat NU Kabupaten Subang” (2020).
} 
2. Terwujudnya masyarakat yang berkeadilan gender.

3. Terwujudnya asa kesetiaan terhadap asas, aqidah dan tujuan NU dalam menegakkan Syariat Islam.

Adapun maksud dan tujuan Fatayat NU ini sebagaimana hasil wawancara penulis dengan ketua Fatayat NU Kabupaten Subang yakni Ibu Hj Unengsih:

"Setelah diangkatnya saya menjadi ketua Fatayat NU Subang memang saya memiliki maksud dan tujuan. Adapun maksud dan tujuannya, saya ingin membentuk wanita muda Islam yang berakhlakul karimah serta memfokuskan dalam bidang kaderisasi. Kenapa saya memfokuskan di bidang kaderisasi, karena dulu Fatayat NU Subang itu kebanyakan ada di daerah utara. Maka dari itu, setelah saya menjadi ketua fokus tujuan saya yakni membentuk Fatayat di setiap PAC. ${ }^{22}$

\section{Kegiatan Fatayat NU Kabupaten Subang Periode 2015-2020}

Adapun kegiatan yang selalu dilaksanakan oleh Fatayat NU Cabang Subang yakni mulai dari kegiatan mingguan, bulanan dan tahunan. Kegiatan Fatayat NU ini menunjang kedalam program kerja yakni:

\section{Pengajian di setiap PAC}

Kegiatan rutinan yang selalu digelar setiap minggunya yakni pengajian yang diadakan oleh setiap PAC. Dimana pengajian ini biasanya diisi dengan ceramah. Untuk waktunya sendiri itu setiap PAC berbeda-beda, menyesuaikan dengan ibu-ibu setempat. Tetapi, karena kebanyakan ibu-ibu Fatayat ini bekerja sebagai pengajar maka biasanya hari sabtu atau minggu menjadi waktu pengajian ini diadakan, karena sabtu atau minggu ini merupakan hari libur mereka.

2. Kunjuangan silaturahmi ke tiap PAC kecamatan se-Kabupaten Subang dalam rangka memperkokoh organisasi Fatayat NU.

Kunjungan ini dilakukan sebulan sekali, dimana kunjungan ini biasanya dilakukan oleh Ketua yang bersilaturahmi ke setiap PAC. Adapun tujuan dari kunjungan ini adalah untuk mempererat silaturahmi serta menjadi ajang evaluasi PAC yang dikunjungi tersebut. Bukan hanya evaluasi saja, tetapi sesekali mereka juga berdiskusi mengenai masalahmasalah terkait perempuan. ${ }^{23}$

\section{PHBI}

\footnotetext{
${ }^{22} \mathrm{Hj}$ Unengsih.

${ }^{23}$ Ibu Aan Isnawati, “'Wawancara' Wakil Sekertaris Fatayat NU Subang” (2020).
} 
Perayaan hari besar dalam Islam itu diantaranya Maulid Nabi, Isra' Mi'raj dan Tahun Baru Hijriah, seperti kita ketahui bagi warga Nahdlatul Ulama perayaan seperti ini sudah sangat biasa, begitu juga dengan Fatayat NU. Perayaan hari besar Islam ini memang belum pernah dilakukan oleh PC Fatayat NU Kabupaten Subang, tetapi di PAC perayaan ini biasa dilakukan. Biasanya PAC akan mengundang Pengurus PC untuk datang ke perayaan tersebut. ${ }^{24}$

\section{PHBI}

Perayaan hari besar dalam Islam itu diantaranya Maulid Nabi, Isra' Mi'raj dan Tahun Baru Hijriah, seperti kita ketahui bagi warga Nahdlatul Ulama perayaan seperti ini sudah sangat biasa, begitu juga dengan Fatayat NU. Perayaan hari besar Islam ini memang belum pernah dilakukan oleh PC Fatayat NU Kabupaten Subang, tetapi di PAC perayaan ini biasa dilakukan. Biasanya PAC akan mengundang Pengurus PC untuk datang ke perayaan tersebut. ${ }^{25}$

\section{Perkembangan Dalam Bidang Kaderisasi Periode 2015-2020}

\section{Studi Kaderisasi}

Kaderisasi adalah proses mempersiapkan calon-calon pemimpin suatu organisasi untuk waktu sekarang dan masa yang akan datang. Tujuan kaderisasi adalah mempersiapkan calon-calon pemimpin demi kesinambungan organisasi, sehingga jika terjadi pergantian pemimpin dapat berjalan mulus karena sudah dipersiapkan. Dengan demikian pengangkatan seorang pemimpin sebaiknya melalui proses kaderisasi. Degan demikian adanya kaderisasi, diharapkan organisasi akan bertahan dalam waktu cukup lama, tidak bersifat ad-hoc dalam mengemban visi dan melaksanakan misinya. ${ }^{26}$

\section{Proses Kaderisasi Fatayat NU Kabupaten Subang}

Kader adalah orang yang dididik untuk menjadi pelanjut tongkat estafet suatu partai atau organisasi, calaon tunas muda, generasi muda. Kader diartikan sebagai para pendukung dan pelaksana cita-cita suatu organisasi. Pengkaderan dikatakan berhasil apabila calon kader berhasil disadarkan tentang apa dan bagaimana dirinya harus berbuat sesuai tujuan yang ingin

\footnotetext{
${ }^{24}$ Isnawati.

${ }^{25}$ Ibu Aan Isnawati, Wakil Sekertaris Fatayat NU Subang (wawancara pada tanggal 17 Juni 2020)

${ }^{26}$ Redatin Parwadi, "Kaderisasi Organisasi Dalam Perubahan," Jurnal Wawasan 12 (2006): $5-6$.
} 
dicapai. Sehingga yang disebut dengan strategi pengkaderan adalah cara jitu yang dilakukan oleh organisasi dalam melakukan serangkaian kegiatan yang berkaitan antara satu dengan lainnya yang ditunjukkan pada usaha proses pembentukan kader dalam upaya mencapai tujuan yang dicita-citakan. Untuk mendapatkan kader-kader yang sesuai dengan kebutuhan organisasi, maka tiap organisasi memiliki kriterianya masing-masing. ${ }^{27}$

Adapun kriteria untuk menjadi kader-kader Fatayat NU, seperti yang telah dipaparkan oleh Ketua Fatayat NU Subang Ibu Hj Unengsih, yaitu:

1. Rekrutmen kader yakni harus orang NU.

2. Usia produktif mulai dari usia 25 tahun hingga usia 45 tahun.

3. Mempunyai keinginan dan semangat untuk mengabdi pada Fatayat dengan ikhlas.

4. Mempunyai dedikasi tinggi dan peduli terhadap permasalahan perempuan.

Sistem rekrutmen yang dilakukan oleh Fatayat NU, yakni menggunakan beberapa jalur.

1. Jalur Pendidikan NU (Lembaga ma'arif, pesantren, sekolah, perguruan tinggi NU)

Rekrutmen anggota fatayat yang pertama itu melalui jalur pendidikan. Dimana, orang-orang Fatayat akan merekrut anggotaanggotanya melalui lembaga pendidikan NU seperti di pesantren, sekolah dan perguruan tinggi NU. Jalur ini mungkin dipilih oleh Fatayat NU karena lebih efektif untuk melakukan pengakaderan.

2. Jalur Kultural (orang tua/suami NU)

Selanjutnya Fatayat merekrut anggota itu melalui jalur Kultural. Dimana, sudah menjadi tradisi sendiri dalam Nahdlatul Ulama jika orang tua atau suaminya yang merupakan orang NU atau berada di keperngurusan NU pasati anak atau istrinya pun akan ikut organisasi NU. Sebagai salah satu contoh yaitu jika suaminya di GP Anshor maka biasanya istrinya di Fatayat, itu sudah sangat lumrah sekali dikalangan Nahdlatul Ulama.

3. Jalur Organisasi yang secara kultural lekat dengan NU (IPPNU, PMII)

Kemudian Fatayat NU juga merekrut anggotanya dari organisasi yang sama yakni di bawah naungan Nahdlatul Ulama, seperti IPPNU dan PMII. Seperti kita ketahui, IPPNU merupakan organisasi khusus para pelajar

\footnotetext{
${ }^{27}$ Farid Noviard, "Kaderisasi Kepemimpinan Pambakal (Kepala Desa) Di Desa Hamalau Kabupaten Hulu Sungai Selatan,” Ilmu Politik Dan Pemerintahan Lokal II (2013): 265.
} 
perempuan NU, sedangkan PMII merupakan organisasi kemahasiswaan $\mathrm{NU} .^{28}$ Di dalam lembaga NU sistem organisasi yang diwadahinya tersusun secara bertahap yakni dimulai dengan IPPNU sebagai wadah bagi para pelajar perempuan NU, PMII sebagai wadah bagi para mahasiswa NU, lalu Fatayat sebagai wadah bagi kaum wanita NU hingga Muslimat sebagai wadah bagi ibu-ibu NU. Untuk tambahan, bukan hanya kader dari PMII saja, Fatayat NU Kabupaten Subang juga merekrut kader dari HMI.

Adapun tujuan kaderisasi Fatayat NU yakni ingin mempersiapkan calon-calon pemimpin demi kesinambungan organisasi, dengan memiliki tujuan yang jelas, Fatayat NU dapat bertahan dalam waktu yang cukup lama. Sehingga misi dalam mewujudkan perempuan yang berkarakter, bermartabat dan mempunyai rasa kesetiaan terhadap azas, aqidah, menegakkan syariat Islam menurut faham ahlussunah waljama'ah, serta membela NKRI ini dapat tercapai.

Tahap selanjutnya yang dilakukan oleh pengurus Fatayat NU yaitu dengan melakukan Pelatihan Kader Dasar. Fatayat NU Subang pernah menyelenggarakan pelatihan kader dasar Fatayat. Pelatihan kader dasar Fatayat itu diisi sejumlah materi tentang Keaswajaan, ke NU-an dan wawasan kebangsaan. Materi tersebut penting untuk dipahami oleh kader Fatayat, guna memperkuat aqidah dan rasa kebangsaan serta memperkokoh persatuan kesatuan dan NKRI. Peserta diklat dari perwakilan PAC seKabupaten Subang yang kemudian langsung dibentuk dan dilantik. Dalam kesempatan itu perwakilan PP Fatayat NU Nadzifah yang juga merupakan anggota DPR RI FPKB menuturkan, pihaknya mengapresiasi diklat ini. hal ini menjadikan organisasi hidup dan meregenerasi. Nadzilah juga meminta agar para kader yang telah ikut diklat serta pengurus PAC setelah dilantik harus membuat program sehingga organisasi berjalan dan tidak diam ditempat. Dengan mengibarkan panji-panji ke-NU-an dan ke-Aswajaan melalui pengajian di majlis-majlis taklim ${ }^{29}$

Dalam Pelatihan Kader Dasar ini, menghadirkan pula sejumlah narasumber seperti pengasuh Ponpes Nurul Anwar Wera Subang KH. Jejen Jaenal Mufidz dan Pimpinan Ponpes Raudhatul Hasanah KH. Abdul Mu'min. Selain dibekali pemahaman seputar keorganisasisan dan NKRI,

\footnotetext{
${ }^{28}$ Gita Anggraini, "Peta Gerakan Perempuan Islam Pasca Orde Baru (Book Review)," 3.

${ }^{29}$ Redaksi, "PC Fatayat NU Kabupaten Subang Latih Kader Baru," 2020, https://pasundanekspres.co.
} 
mereka juga digembleng soal peran perempuan di era kekinian. Ketua Fatayat Subang $\mathrm{Hj}$. Unengsih mengatakan, dengan Pelatihan Kader Dasar ini, ke depan Fatayat memiliki kader yang mayoritas perempuan itu menjadi perempuan hebat. ${ }^{30}$

Setelah melakukan Pelatihan Kader Dasar, Fatayat NU Subang pun menggelar Pelantikan. Pelantikan ini digelar Fatayat NU Kabupaten Subang di Aula Pemkab pada Tanggal 19 Oktober 2019. Fatayat NU Subang melantik PAC Fatayat se-Kabupaten Subang, masa khidmat 2019-2021. Pelantikan dilakukan oleh ketua PC Fatayat NU Kabupaten Subang Hj. Unengsih. Unengsih berharap kepengurusan Fatayat di Tingkat Kecamatan itu bisa lebih produktif dan bersinergi dengan pengurus Kabupaten dalam menjalankan program organisasi. ${ }^{31}$

\section{Hasil yang dicapai}

Pencapain terbesar Fatayat NU Subang pada periode 2015-2020 yakni berhasil melantik PAC se-Kabupaten Subang, total ada 30 PAC yang berhasil dilantik, tetapi sampai saat ini yang aktif $20 \mathrm{PAC}$, yakni: ${ }^{32}$

1) Kecamatan Patok Beusi

2) Kecamatan Ciasem

3) Kecamatan Pamanukan

4) Kecamatan Pusakanagara

5) Kecamatan Legon Kulon

6) Kecamatan Tambakdahan

7) Kecamatan Binong

8) Kecamatan Pagaden Barat

9) Kecamatan Cikaum

10) Kecamatan Purwadadi

11) Kecamatan Pabuaran

12) Kecamatan Kalijati

13) Kecamatan Dawuan

14) Kecamatan Cipunagara

15) Kecamatan Pagaden

16) Kecamatan Cijambe

\footnotetext{
${ }^{30}$ Annas Nasrullah, "Fatayat NU Subang Bekali Kader Sebagai Perempuan Hebat," tintahijau.com, 2020.

${ }^{31}$ Nasrullah.

${ }^{32}$ Dedeh Nurhasanah, "Wawancara - Fatayat NU Ketua Bidang Organisasi, Pendidikan Dan Pengkaderan," (2020).
} 
17) Kecamatan Jalancagak

18) Kecamatan Kasomalang

19) Kecamatan Cisalak

20) Kecamatan Tanjungsiang

Dari pencapaian tersebut, ketua Fatayat NU Subang Hj Unengsih berharap kedepannya Fatayat NU Subang dapat menata dan mengorganisir setiap bidang yang ada dalam naungan organisasi Fatayat NU.

\section{E. Kendala dan Hambatan Fatayat NU}

Fatayat NU sebagai salah satu Badan Otonom di lingkungan NU untuk menaungi perempuan NU dengan batasan usia tertentu. Menurut aturan organisasinya, yang menjadi anggota Fatayat NU yakni perempuan muda yang berusia 25-45 tahun. Melihat segmentasi dengan usia ini, kader Fatayat NU berada dalam rentang usia produktif. Dalam usia tersebut, perempuan berada dalam masa produktif sebagai perempuan bekerja, juga sekaligus produktif secara reproduksi. ${ }^{33}$ Namun dalam keproduktifan tersebut terhambat oleh beberapa faktor, diantaranya yakni:

a. Izin Suami.

b. Hamil, melahirkan, menyususi dan mengurus anak.

c. Pekerjaan/profesi.

Maka dari itu sebagai organisasi kader, Fatayat NU Subang tentu masih memiliki banyak kekurangan. Namun dengan ini, diharapkan Fatayat NU Subang kedepannya bisa lebih baik lagi.

\section{F. Hubungan Fatayat NU Kabupaten Subang dengan Pemerintah}

Sebagai organisasi kemasyarakatan berbasis agama di bawah naungan Nahdlatul Ulama, Fatayat NU Subang banyak melakukan kerja sama dengan pihak pemerintah. Karena NU sendiri mendukung sepenuhnya visi Presiden untuk kemajuan bangsa dan negara. Hubungan Fatayat NU Kabupaten Subang dengan pemerintah, dapat dilihat dari beberapa kegiatan yang pernah diadakan dalam bentuk kerja sama. Contohnya Fatayat NU Kabupaten Subang pernah mengadakan kerjasama dengan KPU, dimana Fatayat NU Subang diminta mensosialisasikan mengenai tata cara pemilihan umum tahun 2019. Dalam kegiatan tersebut Fatayat NU memaparkan mulai

${ }^{33}$ Ai Sadidah, "Fatayat NU, Antara Realita Dan Harapan .," 2020, www.nuonline. 
dari tata cara pelaksanaan pemilu, memperkenalkan calon-calon serta partaipartaimya. ${ }^{34}$

Kemudian, Fatayat NU Kabupaten Subang pun pernah bekerjasama dengan DP2KBP3A. DP2KBP3A merupakan unsur pelaksana urusan pemerintahan daerah dibidang pengendalian Pendudukan dan Keluarga Berencana serta urusan pemerintah daerah dibidang pemberdayaan perempuan dan perlindungan anak. Dengan itu, DP2KBP3A pernah bekerjasama dengan Fatayat NU Subang yakni mengadakan diskusi mengenai ketahanan keluarga dan peranan wanita. ${ }^{35}$

Selain itu, terdapat juga kerjasama Fatayat NU Subang dengan DPR RI. Kerja sama ini diawali dengan adanya penyelenggaraan workshop. Dalam workshop ini Fatayat NU Subang diminta gulirkan program pemberdayaan perempuan. Selanjutnya, kerjasama dilaksanakan pada beberapa waktu yang lalu. Bentuk kegiatan tersebut yakni sosialisasi. Dalam sosialisasi tersebut, membahas mengenai Pancasila, UUD 1945 NKRI dan Bhineka Tunggal Ika. ${ }^{36}$

Seperti yang kita ketahui tahun 2020 dunia dilanda pandemi virus covid-19, begitu pun Indonesia, termasuk Kabupaten Subang. Oleh karena itu pemerintah Subang dengan Fatayat NU Subang turun langsung untuk mengajak masyarakat agar tetap menjalankan protokol kesehatan yang sudah ditetapkan oleh pemerintah. Seperti jaga jarak, selalu menggunakan masker, menjaga kebersihan serta rajin mencuci tangan. Diharapkan dengan begitu, masyarakat sadar akan pentingnya menjalankan protokol kesehatan tersebut. ${ }^{37}$

\section{Simpulan}

Berdasarkan pembahasan di atas maka dapat disimpulkan:

Fatayat NU Didirikan di Surabaya 24 April 1950 M, bertepatan dengan 7 Rajab $1317 \mathrm{H}$. Organisasi yang menghimpun pemudi NU ini memiliki andil besar dalam mempertajam dan memberdayakan kaum perempuan NU. Mengenai siapa yang mula merintisnya yakni sering disebut dengan "Tiga Serangkai" mereka adalah Murtosiyah dari Surabaya,

\footnotetext{
${ }^{34}$ Dedeh Nurhasanah, "Wawancara - Fatayat NU Ketua Bidang Organisasi, Pendidikan Dan Pengkaderan."

${ }^{35}$ Dedeh Nurhasanah.

${ }^{36}$ Dedeh Nurhasanah.

${ }^{37}$ Dedeh Nurhasanah.
} 
Chuzaimah Mansur dari Gresik dam Aminah Mansur dari Sidoarjo. Adapun orang yang paling berjasa atas berdirinya Fatayat NU adalah K. H Mohammad Dahlan, bahkan yang menamai organisasi tersebut dengan nama "Fatayat" adalah beliau.

Adapun awal mula berdirinya Fatayat NU Kabupaten Subang yakni berdiri pada tahun 1985 yang pada waktu itu diketuai oleh Ibu Umi Kulsum atas perintah Ketua PCNU Subang kala itu yaitu Kyai Bustomi. Dimana pada tahun 1985, diadakan sebuah Konferensi Wilayah, yang mana pada Konferensi Wilayah itu bekerjasama dengan NU dan mengikut sertakan juga Fatayat NU untuk bergabung. Karena Konferensi Wilayah inilah Ketua NU Kabupaten Subang Kiai Bustomi membentuk Fatayat NU Kabupaten Subang yang sebelumnya tidak ada.

Proses kaderirasi merupakan proses mempersiapkan calon-calon pemimpin suatu organisasi. Ini juga dilakukan oleh Fatayat NU Kabupaten Subang, dimana dalam proses kaderisasi nya ada beberapa tahapan, mulai dari mencari kader sesuai dengan kriteria yang sudah ditetapkan. Kemudian sistem rekrutmen yang dilakukan oleh Fatayat NU ini yakni menggunakan beberapa jalur. Tahap selanjutnya yang dilakukan oleh pengurus Fatayat NU yaitu dengan melakukan Pelatihan Kader Dasar. Setelah melakukan Pelatihan Kader Dasar, Fatayat NU Subang pun menggelar Pelantikan. Dimana pada pelantikan ini Fatayat NU Kabupaten Subang melantik sebanyak 30 PAC se-Kabupaten Subang pada tahun 2019.

Bukan perkara mudah dalam menjalankan suatu organisasi, terlebih di Fatayat NU, dimana terdapat beberapa kendala dan hambatan yang dihadapi oleh setiap anggotanya. Kendala tersebut yakni izin suami, hamil, melahirkan, mengurus anak dan profesi. Maka dari itu, Fatayat NU Kabupaten Subang masih banyak kekurangan sebagai organisasi.

Seperti induknya Nahdlatul Ulama, Fatayat NU juga merupakan organisasi kemasyarakatan dan keagamaan, dengan ini Fatayat NU Subang banyak melakukan kerja sama dengan pihak pemerintah. Diantaranya pernah bekerja sama dengan KPU, DP2KBP3A dan DPR RI.

\section{Daftar Sumber}

Ai Sadidah. "Fatayat NU, Antara Realita Dan Harapan .," 2020. www.nuonline.

Anggia Ermarini dkk. Hasil Kongres Xv Fatayat Nahdlatul Ulama. Jakarta: 
Pimpinan Pusat Fatayat Nahdlatul Ulama, n.d.

Dedeh Nurhasanah. "Wawancara - Fatayat NU Ketua Bidang Organisasi, Pendidikan Dan Pengkaderan." 2020.

Farid Noviard. "Kaderisasi Kepemimpinan Pambakal (Kepala Desa) Di Desa Hamalau Kabupaten Hulu Sungai Selatan." Ilmu Politik Dan Pemerintahan Lokal II (2013).

Gita Anggraini. "Peta Gerakan Perempuan Islam Pasca Orde Baru (Book Review)," 2020. academia.edu.

Hj Unengsih. "Ketua Fatayat NU Kabupaten Subang." 2020.

Intan Gustina Sari. Peran Kepemimpinan Fatayat Nahdlatul Ulama (NU)

Dalam Mensosialisasikan Kesetaraan Gender. Jakarta: Universitas Islam Negeri Syarif Hidayatullah, 2011.

Isnawati, Ibu Aan. "Wawancara' Wakil Sekertaris Fatayat NU Subang." 2020.

Kulsum, Ummi. "Fatayat Nu - Ketua Fatayat NU Kabupaten Subang Periode Awal." Subang, n.d.

Kuntowijoyo. Pengantar Ilmu Sejarah. Yogyakarta: PT Bentang Pustaka, 1995.

Miskiyah, Al. Sejarah Serdirinya Nahdlatul Ulama Cabang Surabaya. Surabaya: Universitas Islam Negeri Sunan Ampel, 2017.

Nailin Naziyah. "Fatayat NU Dalam Aspek Kemasyarakatan Di Surabaya Tahun 1959-1967." Jurnal Universitas Aielangga, 2015.

Nasrullah, Annas. "Fatayat NU Subang Bekali Kader Sebagai Perempuan Hebat." tintahijau.com, 2020.

Nu.or.id. "No Title." 16 Januari, 2020. ."Struktur Organisasi," n.d.

Nur Khlaik Ridwan. Ensiklopedia Khittah Nahdlatu Ulama Jilid I. Jogjakarta: Ar-Ruzz Media, 2017.

Perwiranegara, H. Alamsjah Ratu. Islam Dan Pembangunan Politik Di Indonesia. Jakarta: CV Haji Masagung, 1987.

Pucuk Pimpinan Fatayat Nahdlatul Ulama. , Profil Fatayat Nahdlatul Ulama. Jakarta: PP Fatayat NU, n.d.

Redaksi. "PC Fatayat NU Kabupaten Subang Latih Kader Baru," 2020. https://pasundanekspres.co.

Redatin Parwadi. "Kaderisasi Organisasi Dalam Perubahan." Jurnal Wawasan 12 (2006). 
Perkembangan Fatayat Nu Kabupaten Subang Dalam Bidang Kaderisasi Periode 2015-2020 | Wiwit Nurhayati Hidayat, Amung Ahmad Syahir, Dina Maliana

Zulfiana Rahmawati dkk. Pengembangan Organisasi. Malang: Universitas Brawijaya, 2012. 
Perkembangan Fatayat Nu Kabupaten Subang Dalam Bidang Kaderisasi Periode 2015-2020 | Wiwit Nurhayati Hidayat, Amung Ahmad Syahir, Dina Maliana 